nidade científica e lembrar sempre o que significa ser par entre pares.

1. Research Trends. Special issue on Big Data. 2012; (30). http://www.researchtrends.com/category/ issue-30-september-2012/.

2. Wutchy S, Jones BF, Uzzi B. The increasing dominance of teams in production of knowledge. Science 2007 ; 316:1036-9.

3. Fanelli D, Glanzel W. Bibliometric evidence for a hierarchy of the sciences. PloS One 2013; 8(6):e66938.

4. Jones TH, Donovan C, Hanney S. Tracing the wider impacts of biomedical research: a literature search to develop a novel citation categorization technique. Scientometrics 2012; 93:125-34.

5. Donovan C. Introduction: future pathways for science policy and research assessment: metrics vs peer review, quality vs impact. Sci Public Policy 2007; 34:538-42.

6. Abbott A, Cyranoski D, Jones N, Maher B, Schiermeier, van Noorden R. Do metrics matter? Nature 2010; 465:860-2.

7. van Noorden R. A profusion of measures. Nature 2010; 465:864-6.

8. Mryglod O, Kenna R, Holovatch Y, Berche B. Comparison of citation-based indicator and peer review for absolute and specific measures of research group excellence. Scientometrics. DOI 10.1007/ s11192-013-1058-9.

9. Derrick GE, Haynes A, Chapman S, Hall WD. The association between four citation metrics and peer rankings of research influence of Australian researchers in six fields of public health. PLoS One 2001; 6:e18521

http://dx.doi.org/10.1590/0102-311XCO040913

Claudio José

Struchiner

Programa de Computação Científica, Fundação Oswaldo Cruz, Rio de Janeiro, Brasil. stru@fiocruz.br

\section{Avaliação da qualidade da produção científica e suas consequências imprevistas e indesejadas: um conceito autoevidente?}

Kenneth, meu querido colega e amigo, gostaria antes de tudo agradecê-lo por assentar as bases de uma discussão que há muito se faz necessária. Você certamente o faz magistralmente e torna a vida de qualquer debatedor interessado em encontrar brechas no seu pensamento extremamente difícil. Assim, entendo que meus comentários a seguir sejam complementares à sua linha de raciocínio, já que agrego mais indagações do que propostas concretas de solução, sem confrontar seus argumentos básicos.

Ao ler seu texto, percebo uma enorme lacuna na definição do que seja qualidade da produção científica. Essa lacuna irá obviamente dificultar qualquer estratégia que tenha como objetivo a avaliação dessa qualidade, quer seja a estratégia proposta de caráter subjetivo ou objetivo, ou ainda utilizando parâmetros qualitativos ou quantitativos. Não podemos encontrar o que procuramos sem a clareza do que estamos a procurar. Situações análogas a essa surgem com frequência, como por exemplo, quando lidamos com a avaliação de inteligência ou qualidade de vida. Eu certamente não me aventuro a abraçar uma definição em particular neste debate, mas chamo a atenção para o fato de que cada participante deste debate terá a sua definição implícita traduzindo diferentes perspectivas individuais, históricas e sociais. Já de antemão é possível prever que não conseguiremos chegar a um consenso mínimo sem um enfrentamento corajoso dessa definição.

Entretanto, para a continuidade do raciocínio, assumamos por um instante que todos temos a mesma noção do que seja qualidade científica. Para a avaliação desse conceito comum, estaríamos mesmo diante de opções que contrastam dimensões como a subjetividade e a objetividade, ou o quantitativo e o qualitativo? Esses contrastes nos remetem aos primórdios da nossa militância na área da saúde coletiva, há algumas décadas, e trazem à superfície um sentimento de dejá vu cuja fragilidade e potencial de fracasso já conhecemos. Acredito já termos superado essa fase e percebido que a combinação das virtudes inerentes a cada dimensão anterior nos permite apreender a realidade com maior robustez e amplitude. É sempre bom lembrar que o processo de decisão dos comitês assessores do CNPq já se baseou em avaliações subjetivas no passado, e 
que esta dinâmica levou a uma disputa fratricida entre áreas do conhecimento, por exemplo, física e matemática versus ciências humanas e saúde coletiva, e atritos internos a cada um dos comitês, opondo pesquisadores que utilizam uma metodologia quantitativa àqueles que utilizam uma metodologia qualitativa. Essa tensão é desnecessária nos dias atuais, já que dispomos de várias abordagens metodológicas que permitem a síntese explícita de um componente subjetivo a um componente objetivo empírico, como o Bayesianismo, entre outras.

Por outro lado, se ainda assim quiséssemos argumentar favoravelmente a um retorno a um passado em que a avaliação da qualidade científica se dava em bases subjetivas, a quem caberia a escolha dos novos árbitros deste sistema? Se tomarmos como exemplo a dinâmica do nosso conselho de pesquisas, esta escolha se dá como fruto das ações lobistas das sociedades científicas e afins, entre outras influências. Como poderíamos garantir que esses novos árbitros assim escolhidos se tornariam os guardiões dos nossos anseios de alocação dos recursos da sociedade baseados numa atividade de pesquisa de qualidade? Não estaríamos apenas substituindo um problema por outro? Quem dentre nós não possui queixas ao sistema de peer review?

Se por um lado o conceito do que seja qualidade da produção científica me parece indefinido, a outra ponta da questão é igualmente ambígua, já que as supostas consequências imprevistas e indesejadas dos atuais processos avaliativos são de difícil caracterização. Há alguns anos, numa conversa informal com Eduardo Massad, professor titular da Faculdade de Medicina da Universidade de São Paulo, sobre este mesmo tema, uma observação nos chamou a atenção. Um exercício de avaliação do corpo docente daquela faculdade, utilizando diferentes métodos, levou a conclusões praticamente idênticas. Essa observação pode ser exemplificada no contexto do presente debate. Não seriam os cinco trabalhos mais importantes de sua produção, identificados pelo próprio autor como proposto por Bruce Alberts, também aqueles mais citados? Minha intuição (avaliação subjetiva) me instigaria a responder a essa questão com um sonoro sim, se eu não estivesse ciente das peças que nossa cognição nos prega.

Nosso sistema cognitivo possui muitas virtudes, mas não menosprezemos suas fragilidades. Kahneman ${ }^{1}$ em seu livro reúne uma infinidade de exemplos que ilustram a nossa dificuldade em lidar com a ilusão da compreensão, e a ilusão de validade, assim como a nossa resistência em "domar" nossas intuições na presença de evidências empíricas. Avanços da psicologia cognitiva

aplicados a esse contexto parecem indicar que a questão não será resolvida contrapondo o subjetivo/qualitativo ao objetivo/quantitativo. A robustez e validade de nossas avaliações só parecem vislumbráveis se a realidade for apreendida por intermédio de uma síntese metodológica dessas abordagens. Não podemos abrir mão de nenhuma fonte de informação. Se utilizadas separadamente, essas avaliações serão ilusórias. A verdade emerge como uma interseção de mentiras 2 .

1. Kahneman D. Thinking, fast and slow. New York: Farrar, Straus and Giroux; 2013.

2. Levins R. Strategy of model building in population biology. Am Sci 1966; 54:421-31.

http://dx.doi.org/10.1590/0102-311XCO050913

Luis Eugenio Portela
Fernandes de Souza

Instituto de Saúde Coletiva, Universidade Federal da Bahia, Salvador, Brasil. luiseugenio@ufba.br

\section{O desafio da avaliação da produção científica}

A atividade científica institucionalizada adquiriu nas sociedades contemporâneas um estatuto de modo privilegiado de produção de conhecimentos válidos e úteis. Do ponto de vista do senso comum, são as aplicações técnicas resultantes da prática científica que parecem conferir esse privilégio e não considerações sobre seus pressupostos ontológicos, epistemológicos ou metodológicos 1 .

Contudo, o desenvolvimento da atividade científica, prévio às aplicações, requer a alocação de recursos pela sociedade. Além disso, a dinâmica da produção de conhecimento científico se caracteriza pelo questionamento permanente ao conhecimento estabelecido, seja ele comum ou científico ${ }^{2}$.

Nesse sentido, a avaliação da produção científica se impõe, tanto a partir de fora, ou seja, da sociedade, em geral, e dos governos ou das empresas que financiam as pesquisas, em particular, quanto a partir de dentro da própria comunidade científica que concorre pelos recursos, defendendo pontos de vistas diferentes ou mesmo contraditórios.

Vale fazer um parêntese para lembrar que submeter-se à avaliação não é uma especificidade da atividade científica. De uma forma ou de outra, toda atividade social é objeto de avaliação. Por exemplo, os políticos, em um regime democrático, são avaliados pelos eleitores, as empresas de capital aberto são avaliadas pelas 